\title{
Thiopurine-induced Myelosuppression with Severe Sepsis in a Patient with Crohn's Disease: A Case Report
}

\author{
Prasanta Debnath $^{1} \odot$, Sujit Nair ${ }^{\circledR}$, Shubham Jain ${ }^{3} \odot$, Suhas Udgirkar ${ }^{4}$, Q Qais Contractor ${ }^{5}$, Pravin $_{\text {Rathi }}^{6} \odot$
}

\begin{abstract}
Thiopurines by their glucocorticoid-sparing property help in maintaining remission for patients with inflammatory bowel disease (IBD), when glucocorticoids are reduced and withdrawn. However, due to bone marrow suppression, it cannot be used in various conditions where it is indicated.

A 17-year-old patient presented with pancytopenia with neutropenic sepsis and alopecia after 3 weeks of starting azathioprine for her underlying Crohn's disease. Thiopurine S-methyltransferase (TPMT;*2, ${ }^{*} 3 \mathrm{~A},{ }^{*} 3 \mathrm{C}$ ) analysis resulted in a wild-type genotype, whereas homozygous Nudix hydrolase 15 (NUDT 15 C415T) variant was positive. Azathioprine was stopped immediately, and she was started on broad-spectrum antibiotics that led to some clinical improvements initially, but later on, the patient developed intestinal obstruction along with postoperative complications leading to death.

In this report, we highlight a case of serious hematological toxicity associated with azathioprine use in a patient with Crohn's disease with homozygous NUDT 15 variant, thus favoring the implementation of a pharmacogenomic approach before starting azathioprine, particularly in the Asian population.

Keywords: Azathioprine toxicity, Crohn's disease, Nudix hydrolase 15, Thiopurine S-methyltransferase.

Indian Journal of Critical Care Medicine (2021): 10.5005/jp-journals-10071-23738
\end{abstract}

\section{INTRODUCTION}

Inflammatory bowel disease (IBD) is a chronic, progressive, immune-mediated disease, occurring in the presence of genetic and environmental risk factors, and consists of ulcerative colitis and Crohn's disease. In about $60 \%$ of IBD patients, azathioprine or 6-mercaptopurine (6-MP) is used to induce and maintain clinical remission. After absorption, azathioprine (85-90\%) is rapidly converted to 6 -MP by a nonenzymatic reaction. Three enzymes, namely, xanthine oxidase (XO), hypoxanthineguanine phosphoribosyl transferase (HGPRT), and thiopurine S-methyltransferase (TPMT), compete to metabolize 6-MP. 6-MP is either metabolized by XO to 6-thiouric acid or by TPMT to 6-methyl mercaptopurine (6-MeMP) or by HGPRT to thioinosine monophosphate (TIMP), which is then metabolized to 6-thioguanine (6-TG). 6-TG is associated with both clinical benefits and bone marrow suppression, whereas 6-MeMP is related to liver toxicity. ${ }^{1,2}$

Nudix hydrolase 15 (NUDT 15), a member of pyrophosphohydrolases, acts on nucleoside diphosphates. It catalyzes the active metabolites of azathioprine, like thioguanosine triphosphates (TGTP) and deoxy-thioguanosine triphosphates (TdGTP), tothioguanosine monophosphates (TGMP) and deoxythioguanosine monophosphates (TdGMP). Thus, it prevents the addition of TGTP and TdGTP into deoxyribonucleic acid (DNA-TG), thus reducing the cytotoxic effects of azathioprine. When the expression of NUDT 15 is downregulated, TGTP level increases significantly with an increased TGTP-to-TGMP ratio. Consequently, DNA-TG also increases in NUDT 15 knockdown cells. Thus, it provides a clear biological role of NUDT 15 variant in thiopurine host toxicity. ${ }^{3,4}$ In this case report, we want to highlight the importance of pharmacogenomics in clinical practice before considering the azathioprine use.
1-6TNMC \& BYL Nair Charitable Hospital, Mumbai, Maharashtra, India
Corresponding Author: Prasanta Debnath, TNMC \& BYL Nair Charitable
Hospital, Mumbai, Maharashtra, India, Phone: +91 8787472958, e-mail:
prasantad89@gmail.com
How to cite this article: Debnath P, Nair S, Jain S, Udgirkar S, Contractor
Q, Rathi P.Thiopurine-induced Myelosuppression with Severe Sepsis in
a Patient with Crohn's Disease: A Case Report. Indian J Crit Care Med
2021;25(2):228-230.
Prior presentation of case report at professional meeting:The case was
presented in abstract form at the American College of Gastroenterology presented in abstract form at the American College of Gastroen
Annual Scientific Meeting, held at San Antonio, TX, USA 2019.

Informed consent for publication of case details: Obtained from patient's relatives.

Source of support: Nil

Conflict of interest: None

\section{Case Presentation}

A 17-year-old female patient presented to us with pain in the abdomen for the past 10 months, acute exacerbation for 1 month, and on-and-off episodes of low-grade fever, loose stools, and vomiting for 5 days. Based on colonoscopy findings and histopathological assessments, she was diagnosed with Crohn's disease around 3 weeks later. She was put on azathioprine $50 \mathrm{mg}(1 \mathrm{mg} / \mathrm{kg})$ once daily, along with prednisolone (30 mg) and mesalamine (2400 mg). Then, azathioprine was increased to $100 \mathrm{mg}(2 \mathrm{mg} / \mathrm{kg})$ after 7 days of initial presentation. Her baseline investigations before starting azathioprine were hemoglobin $(\mathrm{Hb})$ of $9.2 \mathrm{~g} / \mathrm{dL}$, total leukocyte count (TLC) of $9100 / \mu \mathrm{L}$, absolute neutrophil count (ANC) of $5200 / \mu \mathrm{L}$,

(0) Jaypee Brothers Medical Publishers. 2021 Open Access This article is distributed under the terms of the Creative Commons Attribution 4.0 International License (https://creativecommons.org/licenses/by-nc/4.0/), which permits unrestricted use, distribution, and non-commercial reproduction in any medium, provided you give appropriate credit to the original author(s) and the source, provide a link to the Creative Commons license, and indicate if changes were made. The Creative Commons Public Domain Dedication waiver (http://creativecommons.org/publicdomain/zero/1.0/) applies to the data made available in this article, unless otherwise stated. 
Table 1: Detailed investigation chart

\begin{tabular}{|c|c|c|c|c|}
\hline Parameters & March 4, 2018 & March 26, 2018 & March 30, 2018 & April 9, 2018 \\
\hline Azathioprine dose & $50 \mathrm{mg}$ started & \multicolumn{3}{|c|}{$\begin{array}{l}100 \mathrm{mg} \text { (for } 14 \text { days, since March 12, 2018) } \\
\text { Azathioprine stopped since March 26, } 2018\end{array}$} \\
\hline Hemoglobin ( $g / d L)$ & 9.2 & 6.6 & 7.2 & 8.8 \\
\hline Total leukocyte count $\left(\times 10^{3} / \mathrm{mL}\right)$ & 9,100 & 900 & 300 & 3,200 \\
\hline Absolute neutrophil count $\left(\times 10^{3} / \mathrm{mL}\right)$ & 5,200 & 180 & 60 & 1,800 \\
\hline Platelet count & $5,64,000$ & $1,44,000$ & 3,000 & 98,000 \\
\hline Bilirubin (mg/dL) & 0.8 & 1.0 & 0.8 & 1.1 \\
\hline$A S T(U / L)$ & 28 & 32 & 45 & 36 \\
\hline$A L T(U / L)$ & 22 & 20 & 36 & 28 \\
\hline$A L P(I U / L)$ & 148 & 202 & 196 & 158 \\
\hline Protein $(\mathrm{g} / \mathrm{dL})$ & 6.1 & 5.9 & 5.6 & 6.2 \\
\hline Albumin ( $g / d L)$ & 3.2 & 3.0 & 3.0 & 3.1 \\
\hline$L D H(U / L)$ & 320 & 430 & & \\
\hline$C R P(m g / L)$ & 4.64 & 140 & & 78 \\
\hline ESR (mm/1st hour) & 48 & 102 & & \\
\hline Vitamin B12 (ng/mL) & & 436 & & \\
\hline Folate $(\mathrm{ng} / \mathrm{mL})$ & & 12 & & \\
\hline Blood culture & & 3 Culture: no growth & MDR Escherichia coli & \\
\hline Urine culture & & No growth & & \\
\hline 6-Thioguanine (pmol/8 $\left.\times 10^{8} \mathrm{RBCs}\right)$ & & 554 & & \\
\hline
\end{tabular}

Abbreviations: ALP, alkaline phosphatase; ALT, alanine aminotransferase; AST, aspartate aminotransferase; CRP, C-reactive protein; ESR, erythrocyte sedimentation rate; $\mathrm{LDH}$ : lactate dehydrogenase

platelet count of $5,64,000 / \mu \mathrm{L}$, elevated erythrocyte sedimentation rate of $48 \mathrm{~mm} / 1 \mathrm{st}$ hour, and C-reactive protein (CRP) of $4.64 \mathrm{mg} / \mathrm{L}$, with normal liver chemistries (Table 1).

With not much relief in her abdominal complaints, she presented to our center after 3 weeks, with high-grade fever and an increase in pain in the abdomen associated with vomiting. On investigation, she was found to have pancytopenia (normocytic, normochromic anemia with $\mathrm{Hb}$ of $6.6 \mathrm{~g} / \mathrm{dL}$, TLC of $900 / \mu \mathrm{L}$ with an ANC of $180 / \mu \mathrm{L}$, and platelet count of $1,44,000 / \mu \mathrm{L}$ ) with elevated inflammatory markers (CRP, $140 \mathrm{mg} / \mathrm{L}$ ). Vitamin B12 and folate levels were within the normal range. During her hospital stay, the patient started having excessive hair loss as well. The patient was started on broad-spectrum antibiotics (febrile neutropenia regimen) along with Filgrastim (G-CSF analog) at $5 \mu \mathrm{g} / \mathrm{kg} /$ day, which was increased to $10 \mu \mathrm{g} / \mathrm{kg} /$ day, but the patient had gradually falling $\mathrm{Hb}$, TLC, and platelet counts. The least TLC noted was $300 / \mu \mathrm{L}$ with ANC of $60 / \mu \mathrm{L}$ and the lowest platelet count being 3000/ $\mathrm{LL}$. Bone marrow aspiration with biopsy was done, which showed hypoplastic marrow. Despite broad-spectrum antibiotics, cefepime, and linezolid along with antifungals, the patient continued to have fever with three sterile blood culture reports. In course of her hospital stay, the patient also developed closed-loop intestinal obstruction of proximal ileum with hemorrhage within the bowel wall due to severe thrombocytopenia. Multiple transfusions in the form of red blood cell concentrate and single-donor apheresis platelet were given and managed conservatively. Finally, blood culture was repeated, which grew Escherichia coli, which was resistant to multiple drugs but sensitive to Tigecycline and Amikacin. The patient was then started on the same antibiotic, which led to a response in fever after 7 days along with improvement in her cell counts. Genetic analysis for TPMT activity was done, which showed normal TPMT (wild-type) genotype. NUDT 15 variant analysis showed a homozygous NUDT 15 C415T type. After a long hospital stay of 2 months with all supportive treatments, the patient developed intestinal obstruction (stricturing type of Crohn's disease) and was referred for surgery. On the third postoperative day, the patient developed anastomotic site leak with wound infection and sepsis, leading to clinical deterioration and later on the death of the patient.

\section{Discussion}

Azathioprine or 6-MP is an immunosuppressive drug of thiopurine class, effective in the treatment of IBD. Around $10 \%$ of patients with IBD develop adverse events related to treatment. Myelosuppression is the most potentially serious adverse event related to azathioprine use. Though many cases of azathioprine-induced hematological side effects are being reported in the literature, our case remains the first of its kind to report such severe myelosuppression with sepsis.

Previous studies have shown that in large series of 739 patients, azathioprine ( $2 \mathrm{mg} / \mathrm{kg} /$ day) led to bone marrow toxicity in $5 \%$ of population when used for around 12.5 months, and the duration ranged from 2 weeks to 11 years during the treatment. ${ }^{5}$ Moreover, it has been suggested that Asian patients have a low tolerance to full doses of azathioprine and suffer more adverse events. ${ }^{6-10}$ However, all of these studies were based on the evaluation of TPMT genotype and phenotype. Presently, the American Gastroenterological Association (AGA) suggests routine testing of TPMT (enzymatic activity or genotype) to decide the dosing of azathioprine. But no such recommendation exists for NUDT 15.11

Yang et al. in their study have found that the NUDT15 variant (Arg139Cys) was strongly linked with thiopurine-induced early leukopenia in patients with Crohn's disease on thiopurines. ${ }^{12}$ 
Moreover, the sensitivity and specificity of the NUDT15 variant for thiopurine-induced early leukopenia were found to be 89.4 and $93.2 \%$, respectively. A further study from India has found that NUDT15 (C415T) risk allele frequency was $10.7 \%$, with the frequency of wild, heterozygous, and mutant genotypes being 80.6, 17.5, and $1.9 \%$, respectively. Among patients with thiopurine-induced toxicity, $10 \%$ of patients developed myelotoxicity, and all patients were found to harbor NUDT 15 variant. $^{13}$

A recent European study by Schaeffeler et al. has shown that severe hematotoxicity in patients on thiopurines has been associated with genetic polymorphism in both TPMT and NUDT 15. Thirty-one percent of their patient cohort had TPMT variant with NUDT 15 variant seen in 13, and $6 \%$ had both TPMT and NUDT 15 variant. ${ }^{14}$ Similarly, Walker et al. in their casecontrol study on thiopurines in patients with IBD in European ancestry have found that NUDT 15 variant was independently associated with azathioprine-induced bone marrow suppression irrespective of TPMT genotype and thiopurine dose. ${ }^{15}$ Similarly, other studies have also demonstrated an increased risk of thiopurine-induced leukopenia with NUDT15 R139C. . $^{16-18}$

In patients with previous bone marrow suppression, genetic evaluation is of interest as this can predict the future occurrence of a new hematologic accident. Though the presence of heterozygous state or lack of mutation could allow restarting of the drug at a lower dose with careful step-up, the presence of nonfunctional homozygous mutations should lead to complete avoidance of azathioprine or 6-MP. Thus, before initiating thiopurines, screening patients with TPMT mutation remains justifiable for Caucasians, but for Asians, preemptive NUDT 15 variant analysis remains more important in order to prevent future life-threatening complications like myelosuppression.

\section{ORCID}

Prasanta Debnath () https://orcid.org/0000-0001-8294-2031

Sujit Nair (1) https://orcid.org/0000-0002-2993-7353

Shubham Jain ㄴ https://orcid.org/0000-0001-9484-7568

Suhas Udgirkar 으 https://orcid.org/0000-0002-1275-4833

Qais Contractor ib https://orcid.org/0000-0001-7191-8589

Pravin Rathi @ https://orcid.org/0000-0002-1095-3652

\section{References}

1. Gearry RB, Barclay RL. Azathioprine and 6-mercaptopurine pharmacogenetics and metabolite monitoring in inflammatory bowel disease. J Gastroenterol Hepatol 2005;20(8):1149-1157. DOI: 10.1111/j.1440-1746.2005.03832.x.

2. Yarur AJ, Abreu MT, Deshpande AR, Kerman DH, Sussman DA. Therapeutic drug monitoring in patients with inflammatory bowel disease. World J Gastroenterol 2014;20(13):3475-3484. DOI: 10.3748/ wjg.v20.i13.3475.

3. Moriyama T, Nishii R, Perez-Andreu V, Yang W, Klussmann FA, Zhao $X$, et al. NUDT15 polymorphisms alter thiopurine metabolism and hematopoietic toxicity. Nat Genet 2016;48(4):367-373. DOI: 10.1038/ng.3508.

4. Bessman MJ, Frick DN, O'Handley SF. The MutT proteins or 'Nudix' hydrolases, a family of versatile, widely distributed, 'housecleaning' enzymes. J Biol Chem 1996;271(41):25059-25062. DOI: 10.1074/ jbc.271.41.25059.
5. Connell WR, Kamm MA, Ritchie JK, Lennard-Jones JE. Bone marrow toxicity caused by azathioprine in inflammatory bowel disease: 27 years of experience. Gut 1993;34(8):1081-1085. DOI: 10.1136/ gut.34.8.1081.

6. Collie-Duguid ES, Pritchard SC, Powrie RH, Sludden J, Collier DA, $\mathrm{Li} \mathrm{T}$, et al. The frequency and distribution of thiopurine methyltransferase alleles in Caucasian and Asian populations. Pharmacogenetics 1999;9(1):37-42. DOI: 10.1097/00008571199902000-00006.

7. Kumagai K, Hiyama K, Ishioka S, Sato H, Yamanishi Y, McLeod HL, et al. Allelotype frequency of the thiopurine methyltransferase (TPMT) gene in Japanese. Pharmacogenetics 2001;11(3):275-278. DOI: 10.1097/00008571-200104000-00012.

8. Cao Q, Zhu Q, Shang Y, Gao M, Si J. Thiopurine methyltransferase gene polymorphisms in Chinese patients with inflammatory bowel disease. Digestion 2009;79(1):58-63. DOI: 10.1159/000205268.

9. Kim JH, Cheon JH, Hong SS, Eun CS, Byeon JS, Hong SY, et al. Influences of thiopurine methyltransferase genotype and activity on thiopurine induced leukopenia in Korean patients with inflammatory bowel disease: a retrospective cohort study. J Clin Gastroenterol 2010;44(1):e242-e248. DOI: 10.1097/ MCG.0b013e3181d6baf5.

10. Takatsu N, Matsui T, Murakami Y, Ishihara H, Hisabe T, Nagahama T, et al. Adverse reactions to azathioprine cannot be predicted by thiopurine S-methyltransferase genotype in Japanese patients with inflammatory bowel disease. J Gastroenterol Hepatol 2009;24(7):1258-1264. DOI: 10.1111/j.1440-1746.2009.05917.x.

11. Davavala SK, Desai DC, Abraham P, Ashavaid T, Joshi A, Gupta T. Prevalence of TPMT polymorphism in Indian patients requiring immunomodulator therapy and its clinical significance. Indian J Gastroenterol 2014;33(1):41-45. DOI: 10.1007/s12664-013-0374-6.

12. Yang SK, Hong M, Baek J, Choi H, Zhao W, Jung $\mathrm{Y}$, et al. A common missense variant in NUDT15 confers susceptibility to thiopurineinduced leukopenia. Nat Genet 2014;46(9):1017-1020. DOI: 10.1038/ ng.3060.

13. Shah SA, Paradkar MU, Desai DC, Ashavaid TF. Preemptive NUDT15 genotyping: redefining the management of patients with thiopurineinduced toxicity. Drug Metab Pers Ther 2018;33(1):57-60. DOI: 10.1515/ dmpt-2017-0038.

14. Schaeffeler E, Jaeger SU, Klumpp V, Yang JJ, Igel S, Hinze L, et al. Impact of NUDT15 genetics on severe thiopurine-related hematotoxicity in patients with European ancestry. Genet Med 2019;21(9):2145-2150. DOI: 10.1038/s41436-019-0448-7.

15. Walker GJ, Harrison JW, Heap GA, Voskuil MD, Andersen V, Anderson $C A$, et al. Association of genetic variants in NUDT15 with thiopurineinduced myelosuppression in patients with inflammatory bowel disease. JAMA 2019;321(8):773-785. DOI: 10.1001/jama.2019. 0709.

16. Asada A, Nishida A, Shioya M, Imaeda H, Inatomi O, Bamba S, et al. NUDT15 R139C-related thiopurine leukocytopenia is mediated by 6-thioguanine nucleotide-independent mechanism in Japanese patients with inflammatory bowel disease. J Gastroenterol 2016;51:22-29. DOI: 10.1007/s00535-015-1142-4.

17. Zhu X, Wang XD, Chao K, Zhi M, Zheng H, Ruan HL, et al. NUDT15 polymorphisms are better than thiopurine $\mathrm{S}$-methyltransferase as predictor of risk for thiopurine-induced leukopenia in Chinese patients with Crohn's disease. Aliment Pharmacol Ther 2016;44(9):967-975. DOI: 10.1111/apt.13796.

18. Fei X, Shu Q, Hua BZ, Wang SY, Chen ZY, Ge WH, et al. NUDT15 R139C variation increases the risk of azathioprine-induced toxicity in Chinese subjects: Case report and literature review. Medicine (Baltimore) 2018;97(17):e0301. DOI: 10.1097/MD.0000000000010301. 